\title{
Mass Spectra of the Deuteroethylenes
}

\author{
Vernon H. Dibeler, Fred L. Mohler, and M. de Hemptinne ${ }^{1}$
}

\begin{abstract}
Samples of all of the deuteroethylenes have become available in satisfactory purity, and mass spectra have been measured and corrected for isotopic impurities. The mass spectra of cis and trans dideuteroethylene are nearly identical, and the spectrum of the asymmetrical dideuteroethylene is similar to the symmetrical molecules in the mass range 24 to 30. The probability of removing an $\mathrm{H}$ atom from the deuteroethylenes relative to the probability in $\mathrm{C}_{2} \mathrm{H}_{4}$ is equal to the a priori probability times $1.10,(1.10)^{2}$, and $(1.10)^{3}$ in molecules containing 1,2 , and $3 \mathrm{D}$ atoms, and the relative probability of removing a D atom is 0.90 in $\mathrm{C}_{2} \mathrm{D}_{4}$ and is nearly equal to the a priori probability times $(0.90)^{2},(0.90)^{3}$, and $(0.90)^{4}$ in molecules $\mathrm{C}_{2} \mathrm{HD}_{3}, \mathrm{C}_{2} \mathrm{H}_{2} \mathrm{D}_{2}$, and $\mathrm{C}_{2} \mathrm{H}_{3} \mathrm{D}$, respectively. As the factors 1.10 and 0.90 are nearly reciprocals, these ratios can be expressed as positive and negative powers of 1.10. The probabilities of removing 2 , 3, or 4 atoms are powers or products of the probability of removing single atoms, and thus are also positive and negative powers of 1.10. Similar relations are found in the previously published data on deuteroacetylenes.
\end{abstract}

\section{Introduction}

Studies of the mass spectra of hydrocarbon molecules containing one or more deuterum atoms have shown that in the case of paraffins [ 1 to 5$]^{2}$ and simple unsaturated molecules $[6,7]$ the relative probabilities for dissociating hydrogenic atoms from the deuterated molecule relative to the ordinary molecule are not predictable from a priori possibilities alone. In a molecule containing both protium and deuterium, the probability of removing $\mathrm{H}$ atoms is increased, and that of removing D atoms is decreased as compared with removing $H$ from the ordinary compound. Schissler, Thompson, and Turkevich [5] describe this by using two parameters, $a$ and $b$, which give the relative probabilities of removing $\mathrm{H}$ and $\mathrm{D}$ from the deuterated compound as compared with removing $\mathrm{H}$ from the ordinary compound.

Unfortunately these parameters are different for different compounds and also for the same chemical compound containing different numbers of $\mathrm{D}$ atoms. At the present time there is no general theoretical basis for predicting the spectra of deuterated compounds, and the complexity of the problem increases rapidly with the number of carbon and hydrogen atoms in the molecule. For this reason, the availability of samples of all the possible deuterated ethylenes afforded an exceptional opportunity to study the mass spectra of these compounds. The data are useful not only for analytical applications but also to supply additional information on the relation between dissociation probabilities and isotopic structure.

\section{Experimental Details}

Mass spectra were obtained with a Consolidated 21-103 mass spectrometer. The electron energy was nominally $70 \mathrm{v}$, with an anode current of 10.5 $\mu \mathrm{a}$. The temperature of the ion source was maintained at $250^{\circ} \mathrm{C}$. The energy filter at the collector

\footnotetext{
${ }^{1}$ University of Louvain, Belgium
}

${ }_{2}$ Figures in brackets indicate the literature references at the end of this paper. end was grounded to permit ions resulting from metastable transitions to reach the collector. Other procedures for introducing the samples and obtaining the spectra were conventional.

The ethylene was Phillips Research Grade with a minimum purity of 99.77 mole percent as stated by the manufacturer.

The deuteroethylenes, $\mathrm{C}_{2} \mathrm{H}_{3} \mathrm{D}, \mathrm{C}_{2} \mathrm{D}_{3} \mathrm{H}$, and $\mathrm{C}_{2} \mathrm{D}_{4}$, were prepared by the same general methods described briefly by de Hemptinne, Jungers, and Delfosse [8] and in greater detail by de Hemptinne [9]; i. e., the photochemical addition of hydrogen bromide to acetylene and vinyl bromide. The reactions are briefly summarized as:

$$
\begin{aligned}
& \mathrm{HC} \equiv \mathrm{CH}+\mathrm{HBr} \rightarrow \mathrm{H}_{2} \mathrm{C}=\mathrm{CHBr} \\
& \mathrm{DC} \equiv \mathrm{CD}+\mathrm{HBr} \rightarrow \mathrm{HDC}=\mathrm{CDBr}\}+\mathrm{DBr}- \\
& \mathrm{DC} \equiv \mathrm{CD}+\mathrm{DBr} \rightarrow \mathrm{D}_{2} \mathrm{C}=\mathrm{CDBr} \\
& \left\{\begin{array}{l}
\mathrm{H}_{2} \mathrm{BrC}-\mathrm{CHDBr} \\
\mathrm{HDBrC}-\mathrm{CD}_{2} \mathrm{Br} \\
\mathrm{D}_{2} \mathrm{BrC}-\mathrm{CD}_{2} \mathrm{Br}
\end{array}\right\}+\mathrm{Zn} \rightarrow\left\{\begin{array}{l}
\mathrm{H}_{2} \mathrm{C}=\mathrm{CHD} \\
\mathrm{HDC}=\mathrm{CD}_{2} \\
\mathrm{D}_{2} \mathrm{C}=\mathrm{CD}_{2}
\end{array}\right.
\end{aligned}
$$

Bryce L. Crawford, Jr. of the University of Minnesota very kindly provided a sample of 1,1dideuteroethylene. The 1,trans-2-dideuteroethylene and 1,cis-2-dideuteroethylene were part of several samples [10] analyzed for B. S. Rabinovitch of the University of Washington.

As the minimum energy required to form the $\mathrm{C}_{2} \mathrm{H}_{3}{ }^{+}$ion in ethylene is $3.3 \mathrm{ev}$ greater than that required to ionize the molecule [11], the isotopic purity of the deuteroethylenes was determined by using low-energy electrons in a manner similar to that described by Stevenson and Wagner [12] for deuteroparaffins. Corrections for deuteroethylene impurities were made by using successively corracted patterns. Traces of ethanes were observed in some of the samples, but these did not interfere in the low-voltage measurements. Corrections for the contributions of ethanes were made on the basis of patterns computed on a statistical basis, neglecting the $a$ and $b$ factors defined above. The measured isotopic purity of the deuteroethylenes was as follows: $\mathrm{C}_{2} \mathrm{H}_{3} \mathrm{D}, 95$ percent; $1,1-\mathrm{C}_{2} \mathrm{H}_{2} \mathrm{D}_{2}, 88$ percent; 
1 ,trans-2- $\mathrm{C}_{2} \mathrm{H}_{2} \mathrm{D}_{2} .97$ percent 1 , cis-2- $\mathrm{C}_{2} \mathrm{H}_{2} \mathrm{D}_{2}$, percent; $\mathrm{C}_{2} \mathrm{HD}_{3}, 87$ percent, $\mathrm{C}_{2} \mathrm{D}_{4}, 94$ percent.

\section{Results}

The principal ions in the mass spectra of ethylene and five deuteroethylenes are given in table 1 . The relative abundances are tabulated in the conventional manner after correcting for the contributions of ions containing $\mathrm{C}^{13}$ in natural abundance. The spectrum of the 1,cis-2-dideuteroethylene is very similar to

that of the trans isomer and accordingly is omitted from the table. Also omitted are ions with nonintegral values of $m / e$. These "metastable transition" peaks, observed in all of the ethylenes, result from a delay of the order of miscroseconds in the dissociation of two hydrogenic atoms from the molecule ion. The abundances relative to the molecule ion are about 0.1 percent or less, and in general increase somewhat with increased deuterium substitution.

The total ion abundances of the hydrogen group, $\Sigma i_{\mathrm{H}}^{+}$, the $\mathrm{C}_{1}$ group, $\Sigma i_{\mathrm{C}_{1}}^{+}$, and the $\mathrm{C}_{2}$ group, $\Sigma i_{\mathrm{C}_{2}}^{+}$, are given for each molecule at the bottom of the appropriate column. The measured sensitivity (ion current per unit of pressure) of the molecule ion was the same for all of the ethylenes within the estimated error in pressure measurement (about $2 \%$ ).

TABLE 1. Principal ions in the mass spectra of ethylene and deuteroethylenes for 70 -v electrons

\begin{tabular}{|c|c|c|c|c|c|c|}
\hline$m / e$ & $\mathrm{C}_{2} \mathrm{H}_{4}$ & $\mathrm{C}_{2} \mathrm{H}_{3} \mathrm{D}$ & $\stackrel{1,1-}{\mathrm{C}_{2} \mathrm{H}_{2} \mathrm{D}_{2}}$ & $\underset{\mathrm{C}_{2} \mathrm{H}_{2} \mathrm{D}_{2}}{1, \text { rans- }}$ & $\mathrm{C}_{2} \mathrm{HD}_{3}$ & $\mathrm{C}_{2} \mathrm{D}_{4}$ \\
\hline $\begin{array}{l}1 \\
2 \\
3 \\
4\end{array}$ & \begin{tabular}{l}
6.71 \\
0.88 \\
\hdashline-
\end{tabular} & $\begin{array}{l}5.81 \\
1.17 \\
0.26 \\
-\end{array}$ & $\begin{array}{r}3.81 \\
1.70 \\
0.42 \\
.14\end{array}$ & $\begin{array}{r}3.66 \\
1.67 \\
0.45 \\
.09\end{array}$ & $\begin{array}{r}2.10 \\
2.47 \\
0.26 \\
.26\end{array}$ & $\begin{array}{l}3.78 \\
0.64\end{array}$ \\
\hline $\begin{array}{l}12 \\
13 \\
13.5 \\
14 \\
14.5 \\
15 \\
15.5 \\
16 \\
17 \\
18\end{array}$ & \begin{tabular}{c}
3.17 \\
4.68 \\
0.38 \\
7.83 \\
-0.61 \\
\hdashline \\
\hdashline \\
\end{tabular} & \begin{tabular}{c}
3.31 \\
3.34 \\
0.17 \\
5.72 \\
0.28 \\
4.38 \\
\hdashline 0.42 \\
\hdashline \\
\hdashline
\end{tabular} & \begin{tabular}{l}
3.58 \\
2.58 \\
0.11 \\
6.18 \\
0.25 \\
1.16 \\
\hdashline 4.85 \\
0.34 \\
$-\ldots .-$
\end{tabular} & $\begin{array}{c}3.33 \\
1.76 \\
0.06 \\
4.03 \\
0.22 \\
8.19 \\
0.46 \\
.14 \\
\end{array}$ & $\begin{array}{r}3.61 \\
0.97 \\
.04 \\
4.98 \\
0.22 \\
4.05 \\
0.32 \\
5.13 \\
0.28 \\
\end{array}$ & \begin{tabular}{c}
3.78 \\
\hdashline 6.26 \\
\hdashline 0.47 \\
10.2 \\
\hdashline 0.1
\end{tabular} \\
\hline $\begin{array}{l}24 \\
25 \\
26 \\
27 \\
28 \\
29 \\
30 \\
31 \\
32\end{array}$ & $\begin{array}{c}4.62 \\
13.5 \\
67.5 \\
67.9 \\
100.0 \\
\\
\\
\end{array}$ & $\begin{array}{r}4.15 \\
7.65 \\
31.0 \\
50.6 \\
55.6 \\
100.0 \\
\\
\hdashline\end{array}$ & $\begin{array}{r}3.75 \\
4.03 \\
15.0 \\
42.6 \\
39.9 \\
41.9 \\
100.0 \\
\\
\end{array}$ & $\begin{array}{r}3.70 \\
4.07 \\
15.5 \\
41.5 \\
41.6 \\
40.0 \\
100.0 \\
\end{array}$ & $\begin{array}{c}3.35 \\
1.70 \\
9.79 \\
25.8 \\
38.2 \\
40.8 \\
22.7 \\
100.0 \\
-\end{array}$ & $\begin{array}{l}3.04 \\
10.4 \\
63.7 \\
60.8 \\
100.0\end{array}$ \\
\hline$\sum_{i \stackrel{+}{\mathrm{H}}}$ & 7.59 & 7. 24 & 6.07 & 5.87 & 5.09 & 4. 42 \\
\hline$\Sigma_{i \mathrm{C}}^{+}$ & 16.3 & 17. 2 & 18.7 & 17.9 & 19.0 & 20.2 \\
\hline$\sum_{i}{ }_{C_{2}}^{+}$ & 253.5 & 249.0 & 247.2 & 246.4 & 242.3 & 237.9 \\
\hline
\end{tabular}

\section{1. $\mathrm{C}_{2}$-Group Ions}

Two different fragments containing $\mathrm{H}$ and $\mathrm{D}$ atoms contribute to some of the mass peaks in the $\mathrm{C}_{2}$ group of the monodeutero- and the dideuteroethylenes. In order to determine the relative probabilities of dissociating two or more protium atoms and one or more deuterium atoms from these molecules, some assumption must be made concerning the relative amounts of the contributing ions. No assumption need be made in the spectrum of $\mathrm{C}_{2} \mathrm{HD}_{3}$, as each of the ion peaks has only one possible configuration.

In the computation of the deuteromethane spectra, the authors assumed that the probability of removing one atom, either $\mathrm{H}$ or $\mathrm{D}$, from the deutero compounds was equal to the probability of removing $\mathrm{H}$ from $\mathrm{CH}_{4}$, and similarly for removing 2 , 3, or 4 atoms. This cannot be rigorously true for the ethylenes, for it is seen in table 1 that $\Sigma i_{C_{2}}^{+}$decreases regularly with increasing deuterium substitution. It seems reasonable to assume that each of the terms involved in this sum decreases regularly. This is seen to be the case for the loss of four atoms to give $\mathrm{C}_{2}^{+}$. The ratio of relative intensities of $\mathrm{C}_{2}^{+}$of $\mathrm{C}_{2} \mathrm{H}_{3} \mathrm{D}$ to $\mathrm{C}_{2}^{+}$of $\mathrm{C}_{2} \mathrm{H}_{4}$ is 0.898 ; the ratio of $\mathrm{C}_{2}^{+}$of $\mathrm{C}_{2} \mathrm{H}_{2} \mathrm{D}_{2}$ (mean of the values of column.s 4 and 5 of table 1) to $\mathrm{C}_{2}^{+}$of $\mathrm{C}_{2} \mathrm{H}_{4}$ is 0.807 ; the ratio for $\mathrm{C}_{2} \mathrm{HD}_{3}$ is 0.725 , and for $\mathrm{C}_{2} \mathrm{D}_{4}$ is 0.658. These four ratios are almost exactly equal to $0.898,(0.898)^{2},(0.898)^{3}$, and $(0.898)^{4}$.

TABLE 2. Correction factors necessary to calculate the modified monoisotopic spectra of the deuteroethylenes from ordinary ethylene

\begin{tabular}{|c|c|c|c|c|c|}
\hline Ion & $\mathrm{C}_{2} \mathrm{H}_{4}$ & $\mathrm{C}_{2} \mathrm{H}_{3} \mathrm{D}$ & $\begin{array}{c}\mathrm{C}_{2} \mathrm{H}_{2} \mathrm{D}_{2} \\
\text { (average) }\end{array}$ & $\mathrm{C}_{2} \mathrm{HD}_{3}$ & $\mathrm{C}_{2} \mathrm{D}_{4}$ \\
\hline $\mathrm{C}_{2}$ & 1 & $(0.898)$ & $\begin{array}{c}0.806 \\
(0.807)\end{array}$ & $\begin{array}{c}0.724 \\
(0.725)\end{array}$ & $\begin{array}{c}0.651 \\
(0.658)\end{array}$ \\
\hline$\Sigma \mathrm{C}_{2} \mathrm{X}^{\mathrm{a}}$ & 1 & 0.937 & 0.878 & $\begin{array}{c}0.823 \\
(0.851)\end{array}$ & $(0.770)$ \\
\hline$\Sigma \mathrm{C}_{2} \mathrm{X}_{2}$ & 1 & 0.986 & 0.972 & 0.958 & $(0.610)$ \\
\hline$\Sigma \mathrm{C}_{2} \mathrm{X}_{3}$ & 1 & 0.973 & 0.946 & $\begin{array}{c}(0.948) \\
0.920 \\
(0.935)\end{array}$ & $\begin{array}{r}(0.944) \\
-(0.895)\end{array}$ \\
\hline
\end{tabular}

a $\mathrm{X}$ represents both $\mathrm{H}$ and $\mathrm{D}$ atoms.

The first row of table 2 gives these computed ratios, and in parentheses in the second row are the observed ratios. The relative probability of losing 3 atoms from $\mathrm{C}_{2} \mathrm{D}_{4}$ as compared with $\mathrm{C}_{2} \mathrm{H}_{4}$ is observed to be 0.770 , and it is assumed that the ratio will be $(0.770)^{1 / 4}$, $(0.770)^{2 / 4}$, and $(0.770)^{3 / 4}$ in molecules containing 1,2 , and $3 \mathrm{D}$ atoms. Similarly, from the ratio of the $\mathrm{C}_{2} \mathrm{D}_{4}$ values to the $\mathrm{C}_{2} \mathrm{H}_{4}$ values one can compute ratios for the loss of 2 and 1 hydrogenic atoms. These data are presented in table 2 . In $\mathrm{C}_{2} \mathrm{HD}_{3}$ the values for these ratios are observed experimentally and are in satisfactory agreement with the computed values. In $\mathrm{C}_{2} \mathrm{D}_{3} \mathrm{H}$ and $\mathrm{C}_{2} \mathrm{H}_{2} \mathrm{D}_{2}$ the computed ratios will be used as correction terms to derive from the $\mathrm{C}_{2} \mathrm{H}_{4}$ spectrum what might be called the "modified monoisotopic spectra."

The calculations for the individual dissociation probabilities in the $\mathrm{C}_{2} \mathrm{H}_{3} \mathrm{D}$ spectrum are illustrated in table 3 . In column 2 the abundance of $\mathrm{C}_{2}^{+}$and $\mathrm{C}_{2} \mathrm{H}^{+}$are the observed values from table 1 . It is assumed that $\left[\mathrm{C}_{2} \mathrm{H}^{+}+\mathrm{C}_{2} \mathrm{D}^{+}\right]$is equal to the $\mathrm{C}_{2} \mathrm{H}^{+}$ abundance of $\mathrm{C}_{2} \mathrm{H}_{4}$ multiplied by the correction term from table 2 , namely, $13.5 \times 0.937=12.65$. This value minus the observed abundance of $\mathrm{C}_{2} \mathrm{H}^{+}$from column $2(7.65)$ gives the abundance of $\mathrm{C}_{2} \mathrm{D}^{+}$as 5.00 . This value subtacted from the 26 peak of $\mathrm{C}_{2} \mathrm{H}_{3} \mathrm{D}$, 
31.0 (table 1), gives the abundance of $\mathrm{C}_{2} \mathrm{H}_{2}^{+}$as 26.0. Subtracting this from the corrected abundance of $\mathrm{C}_{2} \mathrm{H}_{2}^{+}$of $\mathrm{C}_{2} \mathrm{H}_{4}$, namely, $67.5 \times 0.986=66.5$, gives 40.5 as the abundance of $\mathrm{C}_{2} \mathrm{HD}^{+}$. Continuing in this manner, a final value of 55.9 is calculated for $\mathrm{C}_{2} \mathrm{H}_{2} \mathrm{D}^{+}$ as compared with the observed value of 55.6. This agreement is entirely satisfactory.

Columns 3 and 4 of table 3 give the a priori probabilities and the "a priori abundances" of ions of the $\mathrm{C}_{2} \mathrm{H}_{3} \mathrm{D}$ spectrum calculated from the $\mathrm{C}_{2} \mathrm{H}_{4}$ spectrum. These values are quite different from the observed abundances in column 2, and the ratios of the values in column 2 to the values in column 4 give the "weighting factors" of column 5 .

TABLE 3. Calculation of individual dissociation probabilities and isotope weighting factors for the $\mathrm{C}_{2}$ group of $\mathrm{C}_{2} \mathrm{H}_{3} \mathrm{D}$

\begin{tabular}{|c|c|c|c|c|}
\hline Positive ion & $\begin{array}{c}\text { Relative } \\
\text { abundance }\end{array}$ & $\begin{array}{c}\text { A priori } \\
\text { probability }\end{array}$ & $\begin{array}{c}\text { A priori } \\
\text { abundance } \\
\text { from } \mathrm{C}_{2} \mathrm{H}_{4}\end{array}$ & $\begin{array}{c}\text { Weighting } \\
\text { factor }\end{array}$ \\
\cline { 1 - 4 } $\mathrm{C}_{2}$ & 4.15 & 1 & 4.62 & 0.90 \\
$\mathrm{C}_{2} \mathrm{H}$ & 7.65 & $3 / 4$ & 10.1 & .76 \\
$\mathrm{C}_{2} \mathrm{D}$ & 5.00 & $1 / 4$ & 3.38 & 1.48 \\
$\mathrm{C}_{2} \mathrm{H}_{2}$ & 26.0 & $1 / 2$ & 33.75 & 0.77 \\
$\mathrm{C}_{2} \mathrm{HD}_{\mathrm{C}}$ & 40.5 & $1 / 2$ & 33.75 & 1.20 \\
$\mathrm{C}_{2} \mathrm{H}_{3}$ & 10.1 & $1 / 4$ & 17.0 & 0.60 \\
$\mathrm{C}_{2} \mathrm{H}_{2} \mathrm{D}$ & 55.6 & $3 / 4$ & 50.9 & 1.09 \\
$\mathrm{C}_{2} \mathrm{H}_{3} \mathrm{D}$ & 100.0 & $\ldots$ & & \\
\hline
\end{tabular}

Weighting factors for the other deuteroethylenes have been computed in the same manner and are summarized in table 4. As the observed abundances for the $\mathrm{C}_{2}$ group of ions of 1,1-dideuteroethylene and cis and trans 1,2-dideuteroethylene are nearly the same, the mean values of the abundances have been used to compute the weighting factors for the $\mathrm{C}_{2} \mathrm{H}_{2} \mathrm{D}_{2}$ molecules. The last two observed weighting factors in each column correspond, respectively, to the $b$ and $a$ factors as defined by Schissler, Thompson, and Turkevich [5]. This notation has been used with subscripts 1 to 4 referriag to the number of deuterium atoms in the molecule. As the factors $a$ and $b$ give the respective probabilities of removing one $\mathrm{H}$ or one $\mathrm{D}$ atom from the deuterium substituted molecule relative to the probability of removing $\mathrm{H}$ from $\mathrm{C}_{2} \mathrm{H}_{4}$, it has been commonly assumed that the probability of removing two or more hydrogenic atoms will involve the appropriate powers and products of the $a$ and $b$ factors. These powers and products of $a$ 's and $b$ 's are included in table 4 . There is in most cases approximate agreement between computed and observed values. It should be noted that experimental errors are magnified in the product terms.

It is seen from table 4 that there is a very regular sequence in the values $a_{1}, a_{2}, a_{3}$, and $b_{1}$ to $b_{4}$ of the following type: $a_{2}=a_{1}^{2}, a_{3}=a_{1}^{3}, b_{3}=b_{4}^{2}, b_{2}=b_{4}^{3}, b_{1}=b_{4}^{4}$. Values $a_{1}=1.10$ and $b_{4}=0.90$ give the best fit to the observed values of $a_{1}, a_{2}, a_{3}, b_{2}, b_{3}$, and $b_{4}$. As $b_{4}$ is nearly equal to the reciprocal of $a_{1}$, it is evident that positive and negative powers of a single constant can represent all seven $a$ 's and $b$ 's, and by the relations shown in table 4 can represent all 26 weighting factors. Table 5 is similar to table 4 but with powers of a single constant $K=1.10$ in place of $a$ 's and $b$ 's. The agreement between observed and computed values is actually better than that found in table 4 based on seven observed weighting factors. It is to be noted that this reciprocal relationship between $a$ and $b$ factors results in the regular sequence that is observed in the intensity of $\mathrm{C}_{2}^{+}$as deuterium

TABLE 4. Summary of the isotope weighting factors for the $\mathrm{C}_{2}$ group of the deuteroethylenes

\begin{tabular}{|c|c|c|c|c|}
\hline Positive ion & $\mathrm{C}_{2} \mathrm{H}_{3} \mathrm{D}$ & $\mathrm{C}_{2} \mathrm{H}_{2} \mathrm{D}_{2}{ }^{*}$ & $\mathrm{C}_{2} \mathrm{HD}_{3}$ & $\mathrm{C}_{2} \mathrm{D}_{4}$ \\
\hline $\mathrm{C}_{2}$ & $0.90 \quad a_{1}^{3} b_{1}=0.78$ & $0.81 \quad a_{2}^{2} b_{2}^{2}=0.77$ & $0.73 \quad a_{3} b_{3}^{3}=0.69$ & $0.66 \quad b_{4}^{4}=0.66$ \\
\hline $\mathrm{C}_{2} \mathrm{H}$ & $.76 \quad a_{1}^{2} b_{1}=.71$ & $.60 \quad a_{2} b_{2}^{2}=.64$ & $b_{3}^{3}=.51$ & .... \\
\hline $\mathrm{C}_{2} \mathrm{D}_{\ldots}$ & $1.48 a_{1}^{3}=1.30$ & $1.16 a_{2}^{2} b_{2}=1.06$ & $.97 \quad a_{3} b_{3}^{2}=.86$ & $.77 \quad b_{4}^{3}=.73$ \\
\hline $\mathrm{C}_{2} \mathrm{H}_{2 \ldots}$. & $0.77 \quad a_{1} b_{1}=0.66$ & $0.66 \quad b_{2}^{2}=0.53$ & -..- & - \\
\hline $\mathrm{C}_{2} \mathrm{HD}$. & 1. $20 \quad x_{1}^{2}=1.19$ & $.94 \quad a_{2} b_{2}=.88$ & $b_{3}^{2}=.64$ & .... \\
\hline $\mathrm{C}_{2} \mathrm{D}_{2 \ldots}$ & $\ldots$ & $1.43 a_{2}^{2}=1.45$ & $1.13 \quad a_{3} b_{3}=1.07$ & $.95 \quad b_{4}^{2}=.81$ \\
\hline $\mathrm{C}_{2} \mathrm{H}_{3 \ldots}$ & $b_{1}=0.60$ & $-\ldots$ & -..- & .... \\
\hline $\mathrm{C}_{2} \mathrm{H}_{2} \mathrm{D}$ & $1.09 a_{1}=1.09$ & $b_{2}=0.73$ & .... & .... \\
\hline $\mathrm{C}_{2} \mathrm{HD}_{2} \ldots \ldots$ & ... $\quad$-... & $1.21 \quad a_{2}=1.21$ & $0.80 \quad b_{3}=0.80$ & .... \\
\hline $\mathrm{C}_{2} \mathrm{D}_{3} \ldots$ & $-\cdots$ & 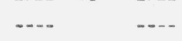 & $1.34 \quad a_{3}=1.34$ & $.90 \quad b_{4}=.90$ \\
\hline
\end{tabular}

*Mean values of 1,1 and $1,2-\mathrm{C}_{2} \mathrm{H}_{2} \mathrm{D}_{2}$

TABLE 5. Isotope weighting factors for the deuteroethylenes compared with the powers of a singe constant, $K=1.10$

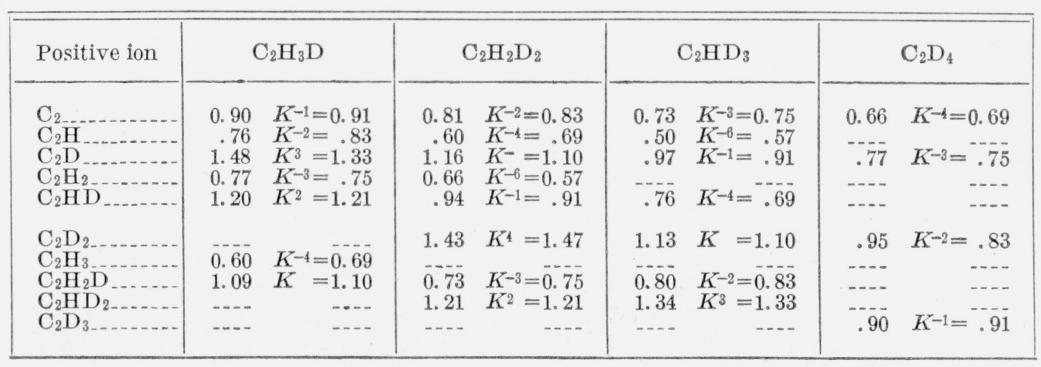


atoms are added to the molecule. This supports the assumptions used to compute the correction factors in table 2 .

These relations can be expressed in terms of one equation containing only one arbitrary constant. The relative probability, $R_{l, m, n}$ of removing $l \mathrm{H}$ atoms and $m \mathrm{D}$ atoms from an ethylene molecule containing $n \mathrm{D}$ atoms and $(4-n) \mathrm{H}$ atoms as compared with the probability of removing $\mathrm{H}$ from $\mathrm{C}_{2} \mathrm{H}_{4}$ is

$$
R_{l, m, n}=A_{l, m, n,} K^{[l n+m(n-5)]}
$$

where $A_{l, m, n}$ is the a priori probability.

\subsection{Ions in the Mass Range 1 to 18}

The more abundant ions in the $m / e$ range 12 to 18 are $\mathrm{C}^{+}, \mathrm{CH}^{+}$, and $\mathrm{CH}_{2}{ }^{+}$, or ions with one or two D atoms instead of $\mathrm{H}$ atoms. There are no significant differences in the spectra of $c$ is and trans $1,2-\mathrm{C}_{2} \mathrm{H}_{2} \mathrm{D}_{2}$. The larger peaks in the spectra of $1,1-\mathrm{C}_{2} \mathrm{H}_{2} \mathrm{D}_{2}$ and $1,2-\mathrm{C}_{2} \mathrm{H}_{2} \mathrm{D}_{2}$ differ in a manner that is consistent with their structure. In the former compound, $\mathrm{CH}_{2}{ }^{+}$and $\mathrm{CD}_{2}{ }^{+}$are large, and in the latter, $\mathrm{CHD}^{+}$is the largest peak. However, a small peak at mass 15 in the spectrum of $1,1-\mathrm{C}_{2} \mathrm{H}_{2} \mathrm{D}_{2}$ must be in large part $\mathrm{CHD}^{+}$, $\left(\mathrm{C}_{2} \mathrm{H}_{2} \mathrm{D}_{2}{ }^{++}\right.$accounts for only a small fraction of the observed intensity). The peak at mass 16 in the spectrum of $1,2-\mathrm{C}_{2} \mathrm{H}_{2} \mathrm{D}_{2}$ is not necessarily $\mathrm{CD}_{2}{ }^{+}$, for an ion $\mathrm{CH}_{2} \mathrm{D}$ is also to be expected. Ionization. processes involving rearrangements of atoms complicate the interpretation of the spectra in this mass range, and a quantitative determination of weighting factors will not be attempted.

The following ions containing three hydrogenic atoms can be identified in spectra of table $1: \mathrm{CH}_{3}{ }^{+}$of $\mathrm{C}_{2} \mathrm{H}_{4}, \mathrm{CH}_{2} \mathrm{D}^{+}$of $\mathrm{C}_{2} \mathrm{H}_{3} \mathrm{D}$, and $\mathrm{CHD}_{2}{ }^{+}$from the $\mathrm{C}_{2} \mathrm{H}_{2} \mathrm{D}_{2}$ molecules and from $\mathrm{C}_{2} \mathrm{HD}_{3}$. Other possible ions of this class are masked by other isomeric ions. A small $\mathrm{H}_{2} \mathrm{O}$ background may mask $\mathrm{CD}_{3}{ }^{+}$ions of $\mathrm{C}_{2} \mathrm{HD}_{3}$ and $\mathrm{C}_{2} \mathrm{D}_{4}$.

Doubly charged ions of half-integer mass number can be identified as follows: $\mathrm{C}_{2} \mathrm{H}_{3}{ }^{++}$of $\mathrm{C}_{2} \mathrm{H}_{4}, \mathrm{C}_{2} \mathrm{H}_{3} \mathrm{D}^{++}$ of $\mathrm{C}_{2} \mathrm{H}_{3} \mathrm{D}, \mathrm{C}_{2} \mathrm{HD}_{2}{ }^{++}$and $\mathrm{C}_{2} \mathrm{HD}^{++}$of $\mathrm{C}_{2} \mathrm{H}_{2} \mathrm{D}_{2}$, and $\mathrm{C}_{2} \mathrm{HD}_{3}{ }^{++}, \mathrm{C}_{2} \mathrm{HD}_{2}{ }^{++}$, and $\mathrm{C}_{2} \mathrm{HD}^{++}$of $\mathrm{C}_{2} \mathrm{HD}_{3}$. This indicates that doubly charged ions containing 2,3 , and 4 hydrogenic atoms are present in all the spectra, with the ions of even molecular weight masked by singly charged ions.

It is apparent from table 1 that the relative abundance of the $\mathrm{C}^{+}$ions increases as the number of $\mathrm{D}$ atoms in the molecule increases, in contrast to the variation of $\mathrm{C}_{2}^{+}$ions with increasing deuterium content. If an average value of 3.45 is taken for the $\mathrm{C}^{+}$ions of the $\mathrm{C}_{2} \mathrm{H}_{2} \mathrm{D}_{2}$ molecules, then the abundance of $\mathrm{C}^{+}$from the deuterated molecules is $(1.043)^{x}$ times the abundance of $\mathrm{C}^{+}$from $\mathrm{C}_{2} \mathrm{H}_{4}$ where $x$ is the number of $\mathrm{D}$ atoms in the molecule.

The sum of the hydrogenic ions decreases progressively from $\mathrm{C}_{2} \mathrm{H}_{4}$ to $\mathrm{C}_{2} \mathrm{D}_{4}$ as the number of $\mathrm{D}$ atoms increases, but this decrease is not accurately represented by a power sequence. Weighting factors computed for $\mathrm{H}^{+}$ions (observed abundances divided by $\mathrm{H}^{+}$of $\mathrm{C}_{2} \mathrm{H}_{4}$ times the a priori probability of removing $\mathrm{H}$ atoms) are $1.15,1.13$, and 1.25 for $\mathrm{C}_{2} \mathrm{H}_{3} \mathrm{D}, \mathrm{C}_{2} \mathrm{H}_{2} \mathrm{D}_{2}$ (mean value), and $\mathrm{C}_{2} \mathrm{HD}_{3}$, respectively. Weighting factors for $\mathrm{D}^{+}$are 0.49 for $\mathrm{C}_{2} \mathrm{HD}_{3}$ and 0.56 for $\mathrm{C}_{2} \mathrm{D}_{4}$. $\mathrm{H}_{2}{ }^{+}$makes a contribution to the mass 2 peaks of $\mathrm{C}_{2} \mathrm{H}_{3} \mathrm{D}$ and $\mathrm{C}_{2} \mathrm{H}_{2} \mathrm{D}_{2}$, and this cannot be accurately evaluated. The weighting factor for producing $\mathrm{D}^{+}$ is somewhat less than 0.50 for $\mathrm{C}_{2} \mathrm{H}_{2} \mathrm{D}_{2}$ and probably less than 0.5 for $\mathrm{C}_{2} \mathrm{H}_{3} \mathrm{D}$. The data do not show any regular trend in weighting factors such as is found for the $\mathrm{C}_{2}$ group of ions.

It is of interest that the ion $\mathrm{HD}^{+}$has about the same relative abundance in the different $\mathrm{C}_{2} \mathrm{H}_{2} \mathrm{D}_{2}$ molecules. That is, the abundance is the same whether or not the two deuterium atoms are on the same carbon atom.

\section{Discussion}

Delfosse and Hipple [6] have previously published the mass spectrum of a cis-trans mixture of 1,2$\mathrm{C}_{2} \mathrm{H}_{2} \mathrm{D}_{2}$. The relative intensities of the $\mathrm{C}_{2} \mathrm{H}_{2} \mathrm{D}_{2}$ and $\mathrm{C}_{2} \mathrm{H}_{4}$ spectra reported by them are entirely consistent with the results obtained in this research.

An interesting and unexpected feature of the experimental results is that in the $\mathrm{C}_{2}$ mass range there is no appreciable difference between the mass spectra of $1,1-\mathrm{C}_{2} \mathrm{H}_{2} \mathrm{D}_{2}$ and cis and trans $1,2-\mathrm{C}_{2} \mathrm{H}_{2} \mathrm{D}_{2}$. The weighting factors remain the same whether there are two D atoms on one carbon atom or one on each carbon atom. Appearance potential measurements [11] indicate that production of $\mathrm{C}_{2} \mathrm{H}_{2}{ }^{+}$from $\mathrm{C}_{2} \mathrm{H}_{4}$ involves the production of $\mathrm{H}_{2}$ rather than atoms of hydrogen, and $\mathrm{H}_{2}$ is also formed when 3 or $4 \mathrm{H}$ atoms are removed. The present results suggest that the hydrogenic molecule is formed with equal probability whether the two atoms are on the same carbon atom or not. This cannot be explained by the assumption of complete mixing of $\mathrm{H}$ and $\mathrm{D}$ atoms in the ionization process, for the fragment ions in the $\mathrm{C}_{1}$ range reflect the molecular structures. There is some rearrangement of hydrogenic atoms, but it is relatively unimportant.

The progressive increase in $\mathrm{C}^{+}$and $\Sigma i_{C_{1}}$ with increasing number of $\mathrm{D}$ atoms in the molecule is in marked contrast to the decrease of $\mathrm{C}_{2}{ }^{+}$and $\Sigma i_{\mathrm{C}_{2}}$ as the number of $\mathrm{D}$ atoms increases. This interesting difference is not entirely unexpected, as Stevenson and Wagner [4] discuss in a general way the theoretical basis for two opposing effects of heavy isotopes on the probability of dissociation.

The analysis of the data in the $\mathrm{C}_{2}$ range of the deuteroethylenes as given in tables 4 and 5 shows a very striking relationship between the "weighting factors" for removal of $\mathrm{H}$ and $\mathrm{D}$ and the number of $\mathrm{D}$ atoms in the molecule. The powers of a single constant assigned according to a definite system or pattern account for all 26 weighting factors, at least to a fairly good approximation. A relationship of this kind might be expected in other deuterated hydrocarbons. The only clear case of such a relationship among the molecules already studied is acetylene.

A previous publication [7] gives the mass spectra of $\mathrm{C}_{2} \mathrm{H}_{2}, \mathrm{C}_{2} \mathrm{HD}$, and $\mathrm{C}_{2} \mathrm{D}_{2}$, and from these data the weighting factors given in table 6 for dissociation of $\mathrm{H}$ and $\mathrm{D}$ have been computed as in table 3 for the 
ethylenes. The table shows that powers of a single constant $K=1.13$ represent quite accurately the five weighting factors. The weighting factors for dissociation of $\mathrm{H}, \mathrm{D}, \mathrm{HD}$, and $\mathrm{D}_{2}$ from the acetylenes $\mathrm{C}_{2} \mathrm{HD}$ and $\mathrm{C}_{2} \mathrm{D}_{2}$ are related in the same way as they are in the ethylenes $\mathrm{C}_{2} \mathrm{H}_{2} \mathrm{D}_{2}$ and $\mathrm{C}_{2} \mathrm{D}_{4}$, except that the constant is 1.13 in the acetylenes and 1.10 in the ethylenes.

TABLE 6. Acetylene weighting factors compared with powers of $K=1.13$

\begin{tabular}{|c|c|c|c|c|}
\hline \multirow{3}{*}{$\begin{array}{l}\mathrm{C}_{2} \\
\mathrm{C}^{2} \mathrm{H} \\
\mathrm{C}^{2} \mathrm{D}\end{array}$} & \multicolumn{2}{|r|}{$\mathrm{C}_{2} \mathrm{HD}$} & \multicolumn{2}{|r|}{$\mathrm{C}_{2} \mathrm{D}_{2}$} \\
\hline & & $\begin{array}{l}K^{-1}=0.88 \\
K^{-3}=.69\end{array}$ & 0.79 & $K^{-2}=0.78$ \\
\hline & & $K^{2}=1.28$ & .86 & $K^{-1}=.88$ \\
\hline
\end{tabular}

Schissler, Thompson, and Turkevich [5] have found that there is a roughly linear relation between the weighting factors for removing $\mathrm{H}$ and $\mathrm{D}$ from the methanes and the number of $\mathrm{D}$ atoms in the molecule. They report values for the $a$ factor as 1.23 , 1.48 , and 1.80 in molecules containing 1,2 , and $3 \mathrm{D}$ atoms. These $a$ factors can be quite accurately represented as $1.22,(1.22)^{2}=1.49$, and $(1.22)^{3}=1.81$, corresponding to the relation found in the ethylenes. However, the $b$ factors apparently are not related to each other and to the $a$ factors as they are in the ethylenes. It is to be noted that the researches of two of the authors [3] and of Schissler et al. [15] on the deuteromethanes are not in good agreement, and in the opinion of the authors the isotopic purity and the isotopic analyses leave much to be desired in both researches. The deuteromethane spectra deserve further research when compounds of better isotopic purity become available. Obviously the computation of weighting factors depends rather critically on the isotopic purity of the mass spectra.

\section{References}

[1] M. W. Evans, N. Bauer, and J. Y. Beach, J. Chem. Phys. 14, 701 (1946).

[2] J. Turkevich et al., J. Am. Chem. Soc. \%o, 2638 (1948).

[3] V. H. Dibeler and F. L. Mohler, J. Research NBS 45, 441 (1950) RP2155.

[4] D. P. Stevenson and C. D. Wagner, J. Chem. Phys. 19, 11 (1951).

[5] D. O. Schissler, S. O. Thompson, and J. Turkevich, Discussions Faraday Soc. 10, 46 (1951).

[6] J. Delfosse and J. A. Hipple, Phys. Rev. 54, 1060 (1938).

[7] F. L. Mohler and V. H. Dibeler, Phys, Rev, 72, 158 (1947); F. L. Mohler et al., J. Research NBS 48, 188 (1952) RP2304.

[8] M. de Hemptinne, J. Jungers, and J. M. Delfosse, J. Chem. Phys. 6, 319 (1938).

[9] M. de Hemptinne, Les isotopes, 7ieme Conseil de chimie Solvay, p. 262 (1948).

[10] J. E. Douglas and B. S. Rabinovitch, J. Am. Chem. Soc. 74, 2486 (1952).

[11] P. Kusch, A. Hustrulid, and J. T. Tate, Phys. Rev. 52, 843 (1937).

[12] D. P. Stevenson and C. D. Wagner, J. Am. Chem. Soc. 7\%, 5612 (1952)。

Washington, March 16, 1954. 